\title{
Female Mechanical Engineering Students' Career Decisions and Development: A Case Study of University Undergraduate Students
}

\author{
Luis M. Dos Santos \\ Woosong University, \\ 196-5 Jayang Dong, \\ Daejeon 34514, South Korea
}

DOI: https://doi.org/10.36941/jesr-2021-0046

\begin{abstract}
Mechanical engineering is one of the popular university majors for engineering students, particularly female students. However, due to the social stereotypes and social stigma, female mechanical engineering students and professionals may face difficulties and discriminations due to their gender. Although women are always encouraged to apply for mechanical engineering programmes, only approximately $20 \%$ of the mechanical engineering student populations are women. There is a need to increase the student population, particularly for women students. Based on the Social Cognitive Career Theory, this study sought to understand why women would decide to join the mechanical engineering study and join the field for long-term development. The results indicated that the personal, academic, and career interests in engineering and science always drive their decision-making process. This study's results enable engineering school leaders and department heads to reform their curricula and instructions for female students and their internship directions for students, from multiple perspectives.
\end{abstract}

Keywords: career decision, engineering, female engineering students, mechanical engineering, Social Cognitive Career Theory, women

\section{Introduction}

\section{$1.1 \quad$ Research background}

Engineering is a profession that faces human resource shortages due to a high demand for qualified professionals and workers. In the United States, many colleges and universities have established both undergraduate and postgraduate programmes to train entry-level and experienced professionals for different management teams (Hernandez-de-Menendez \& Morales-Menendez, 2019).

Due to technical, financial, and industrial developments, mechanical engineering requires many professionals and engineers. Although there are no limitations for entering and studying the engineering majors, mechanical engineering is traditionally viewed as a male-oriented profession (Cech \& Rothwell, 2018). In other words, female students and professionals are less likely than males are to enter this profession because of the gender barriers arising from its social stigma and stereotypes (Wu et al., 2020) and the female students' personal interests and perception of opportunities for career development. 
During the 2017/2018 academic year in the United States, 31,936 bachelor's degrees were awarded to mechanical engineering graduates. However, only $14.8 \%$ of those graduates were female professionals, whilst more than $80 \%$ of the graduates were males. Low populations of female students were also significant in all engineering fields. Furthermore, the report indicated that from 2009 to 2017, the percentage of female students increased by less than 3\%, from $18 \%$ (2009) to $21.3 \%$ (2017). Because the population of female students increased so slightly, the differences between the two gender groups are of vital concern (Roy, 2019). Although both males and females have the same level of abilities and managerial skills, females tend to possess relatively stronger communication and interpersonal management skills. In contrast, males tend to have relatively stronger logical and mathematical skills. Therefore, a better balance between male and female engineering professionals could increase the profession's overall progression towards a balance of skills between the two groups of people.

\subsection{Statement of the Problem}

According to a recent report by the United States Bureau of Labor Statistics, in 2018, 57.1\% of all U.S. women participated in the labour force, whereas $69.1 \%$ of all men did (Women in the Labor Force: A Databook, 2019). Several elements can influence the motivations and reasons why women decide to work. From 1970 to 2018, an increasing number of women decided to pursue higher education degrees and programmes, in response to the encouragement of the government and university policies. In addition, unlike in the previous century, during which women tended to work as housewives as their long-term career, nowadays women with some college education tended to work at least half-time to maintain their personal finances and development (Annabi \& Lebovitz, 2018). Moreover, due to a retirement wave, contemporary women need to work to fill the gap of human resource shortages. Particularly in mechanical engineering, the demands for female professionals are very high in response to various elements and factors of human resource management (Firdaus et al., 2020). However, the current statistics on engineering feature little to attract and motivate women to join the field of mechanical engineering. The researcher arrived at the following reasons for the profession's lack of attractiveness to women:

1) Social stereotypes: The field of mechanical engineering is considered a man's profession, and in fact one in which women should not study the subject matter even if they have an interest in doing so (Firdaus et al., 2020).

2) Social stigma: Women in mechanical engineering may be viewed as being rude because they work in the construction field with men (Strachan et al., 2018).

3) Academic stereotypes: peers, teachers, parents, school counsellors, and relatives may suggest that women should pursue liberal arts majors instead of vocation-oriented subjects, such as engineering and the sciences (Weston et al., 2020).

4) Earning differences: Even when both men and women hold the same position and title, women usually receive a lower salary and fewer benefits than their male co-workers do (White, 2018).

5) Career opportunities: The workplace environment for mechanical engineering usually requires heavy labour and weight lifting. Those job features may limit female applicants (Tao, 2018).

6) Academic interests: At this time, women usually are more interested in pursuing liberal arts subjects than vocational programmes (Fuesting et al., 2017).

\subsection{Purpose of the study}

An undergraduate mechanical engineering programme in the United States was selected for the investigation. Although women are always encouraged to apply for mechanical engineering programmes, only approximately $20 \%$ of the student populations in mechanical engineering currently are women. There is a need to increase the student population, particularly for women students 
(Strachan et al., 2018).

Furthermore, although the engineering-student population of women is low (i.e., roughly $20 \%$ ), female enrolment in such programmes still exists. Therefore, it is important to capture their understanding, motivations, reasons, and experiences in relation to their career decisions, in order to be able to reform and enhance human resources planning and solution(s).

Finally, for the long-term professional development of the field of mechanical engineering, gender inequality should be reformed and enhanced in order to exercise sustainable development of human resources management (Strachan et al., 2018). Otherwise, the male professionals will monopolise the profession, and women will not have significant potential for career promotions.

Building upon the theoretical framework and the purposes of this study, our research was guided by two research questions:

1) Why do female mechanical engineering students decide to study this major?

2) Why do potential female mechanical engineers decide to pursue long-term career development in this male-oriented profession?

\subsection{Theoretical framework: Social Cognitive Career Theory}

The Social Cognitive Career Theory (Lent et al., 1994; Lent \& Brown, 1996) has been employed historically to explore and understand the career decisions and career development of a group of female mechanical engineering students in an undergraduate programme in the United States. Over the years, researchers have merged different elements of the theory on the basis of social and occupational development. As a result, the current version of Social Cognitive Career Theory is likely to follow an edited version by (Dos Santos, 2020). The Social Cognitive Career Theory outlines three major factors that can influence individuals' career decisions:

1) Career-related interests

2) Performance and persistence in education and occupational pursuits

3) Academic and career achievements

The present study was based on the Social Cognitive Career Theory (Dos Santos, 2020; Lent et al., 1994; Lent \& Brown, 1996). The study explored the two research questions and outlined the resulting human resource suggestions for leaders and managers in mechanical engineering.

\section{Methodology}

\subsection{Case study}

The case study methodology was employed to investigate a particular group of female engineering students in a university in the United States. According to Yin (2012), case study methodology allows the researchers to understand the social phenomenon in a designated location, for a group of focused individuals, a time duration etc. Based on this study's purpose, the researcher wants to understand how female mechanical engineering students in an undergraduate programme in the United States share their career decision and career development. Therefore, the case study meets the requirements and criteria (Yin, 2012).

\subsection{Participants and recruitment}

The researcher collected qualitative data from 21 female mechanical engineering students (i.e. undergraduate programme from first to final-year). The purposive sampling strategy (Merriam, 20o9) was employed. The researcher first contacted the department head for potential research. After the researcher received the department leaders' approval, the administrator forwarded the email invitation letter with the potential participants' research protocol. After several discussions, 21 participants decided to join this study. 
The researcher contacted each participant for the data collection and further discussions as most of the participants believed that an online-based data collection technique might meet their expectation. Therefore, the online-based data collection was employed.

\subsection{Data collection}

Two types of data collection tools were employed, including online-based interview sessions (i.e. two sessions per participant) and focus group activities (i.e. seven students per group) (Morgan, 1998). First of all, the participants contacted the researcher's email based on the forwarded protocol and the invitation letter from the school administrator(s). The researcher discussed the data collection (i.e. online-based interview) and arranged the online-based interview sessions (i.e. two sessions per each participant). Each interview session was hosted from 67 to 89 minutes.

After the 42 online-based and individual interview sessions, the researcher arranged the focus group activities (i.e. online-based). To increase the density of the focus group activities, each focus group activity only involved seven participants. Therefore, three sessions of focus group activities were hosted. The focus group activities were hosted from 78 to 103 minutes.

During each of the data collection sessions, the audio-recorder was used to mark down the important messages. All agreed with the arrangement.

\subsection{Data analysis}

After the researcher completed the data collection procedures, the researcher transcribed the voicebased data into written transcripts for further data analysis. First of all, the researcher re-read the materials multiple times in order to categorise the meaningful connections and themes of the materials (i.e. both interview and focus group activity data). Second, the researcher employed the open-coding technique (Strauss \& Corbin, 1990) in order to merge massive data into first-level themes and subthemes. At this stage, 20 themes and 21 subthemes were grouped.

Third, the researcher continued to employ the axial-coding technique (Strauss \& Corbin, 1990) for further data analysis. After the researcher further narrowed down the first-level themes and subthemes. The second-level themes and subthemes were merged. As a result, two themes and two subthemes were yielded.

\subsection{Human subject protection}

The protection of privacy and individuals' personal information was the most important part of this study. Therefore, the researcher employed all potential ways and directions to protect the personal data of the participants and the school.

Therefore, all the signed and unsigned agreements, personal contacts, emails, audio-records, written transcripts, computer, and related materials were all locked in a password protected cabinet. Only the researcher has the rights to read the materials. After the completion of this study, the related materials were deleted and destroyed in order to protect personal information.

For the results, each participant was assigned a pseudonym in order to protect the personal background. Also, as the information of the sites (i.e. university and department) did not impact the results of the study, the researcher masked the information the university as well.

\section{Findings and discussion}

Using 21 individual interview sessions and three focus group activities, the researcher gathered meaningful sharings and data from the participants. Although the participants were from different regions, backgrounds, families, and religious groups, most shared a similar understanding and perspective about their motivations, reasons, and career decisions for pursuing mechanical engineering 
as their major and the focus of their long-term career development after university. Although the researcher was unable to interact with the participants in-person due to the social distancing recommendation, all were willing to spend considerable time in sharing their responses to the researcher's questions.

According to the guidelines of the Social Cognitive Career Theory, people's career-related interests, their performance and persistence in educational and occupational pursuits, and their academic and career achievements are the three most likely influences on their decisions at different levels. On the basis of the data, the researcher identified two themes and four subthemes to answer the two research questions. Table 1 outlines those themes and subthemes.

Table 1. Themes and subthemes of the study

\begin{tabular}{|l|l|}
\hline \multicolumn{2}{|l|}{ Themes and Subthemes } \\
\hline The students' interest in engineering and science \\
\hline & Development as a result of high school courses and field trips \\
\hline & Evolution from an undecided major to a full-time mechanical engineering student \\
\hline The students' academic and career interests \\
\hline & Interest in interdisciplinary engineering \\
\hline & Potential for career development and opportunities in the future robot industry \\
\hline
\end{tabular}

\subsection{Students' interest in engineering and science}

The researcher used the theme of students' interest in engineering and science to answer the first research question of why female mechanical engineering students decide to study that major. All 21 participants expressed that their interest in engineering, particularly mechanical engineering and sciences, developed as a result of their academic influences from high school and university teachers and course materials. Although a previous study had indicated that female students and professionals tended to focus on liberal arts studies, these groups of participants expressed their strong interests in science and technology. As several said, “... I don't think science is only for men, women can also have the interests in engineering and technology ... I believe both men and women should have their interests in any subjects ... engineering and technology is one example" (P\#20, Interview). Another participant also shared her ideas about her experiences, saying, "I can see th[at] engineering and mathematics are all in our society ... from trees to buildings, and even the bookshelf ... it is all about engineering ... we should all have the equal learning opportunity and knowledge ... gender is not an issue ... (P\#3, Interview)

\subsubsection{Development as a result of high school courses and field trips}

Fifteen participants had decided to major in mechanical engineering during their high school voyage. Ten participants expressed that their high school course in Advanced Placement Physics C: Mechanics, and other related courses, inspired their motivation to learn mechanical engineering and were the reason they chose it as their major. Several significant sharings were captured,

... the AP Physics course was my milestone for mechanical engineering learning ... I completed my physics course during $10^{\text {th }}$ grade with the highest honour ... so I completed the AP course in mechanics and AP physics and algebra with the same highest honours as well ... my high school courses led my major ... (P\#5, Focus Group)

Without taking the AP Physics and AP Statistics courses, ... I wouldn't [have] join[ed] the mechanical engineering major ... but these two courses ... helped me to find out my interests in engineering and sciences ... (P\#18, Interview) 
... high school education always changed how I view[ed] university education and my potential job development after university ... I believed that the AP courses in physics and environmental sciences could be the stepping stone for me to learn some university-level courses and programmes in general ... without these courses ... or early college-level courses ... I would not know what to learn ... but these courses allowed me to step into college during high school (P\#1, Interview)

In addition to the participants' high school courses, their field trips to museums, factories, and plantations also increased their understanding and experiences. A previous study (Basten et al., 2014) had indicated that field trips to local sites and museums might increase and confirm secondary school students' motivations and decisions for a career choice. Two sharings in that regard was captured,

... I went to the science museum multiple times during my high school field trips ... I learnt and gained my interests of sciences and engineering from these trips ... the guides and my physics teachers explained the orders and structures to me in detail ... many of us (i.e., classmates) were impressed ... (P\#16, Focus Group)

... the science museum always opens my eyes to different science subjects and ideas ... I learned how to develop robots and how robots were created by scientists and experts in mechanical engineering ... I built up my interests in this field because of the meaningful trip ... high schools should always bring their students to different trips to create some ideas from their students (P\#2, Focus Group)

\subsubsection{Evolution from an undecided major to a full-time mechanical engineering student}

The six other participants had joined the university as an undecided major and declared their major in mechanical engineering during the second year of their voyage. All participants were impressed by their introduction to mechanical engineering and related courses during their first year at university. As a result, all declared mechanical engineering as their major and continued along that pathway. Two significant statements of feedback were captured,

... I like engineering in general ... but I don't know which engineering I should learn ... I completed three engineering courses and the mechanical engineering about robots and machines ... are interesting and useful ... I think the university courses changed my mindset ... (P\#11, Interview)

... I took foreign languages, literature, and psychology during my first term ... but I like mathematics, physics, statistics, and engineering more ... until I completed the mechanical engineering course ... I declared my major in this, as I love robots ... (P\#15, Interview)

In short, in accord with the guidelines of the Social Cognitive Career Theory (Dos Santos, 2020; Lent et al., 1994; Lent \& Brown, 1996), the participants' previous experiences from their school environment strongly impacted and influenced these two groups of female participants' selection of a university major and their academic decisions, and particularly guided how they would explain and make sense of how they made their career decisions (Harvey et al., 2014). All believed that their experiences and interests should play more important roles than gender in their choices for a university major (Rinke, 2009).

\subsection{The students' academic and career interests}

The researcher used the theme of academic and career interests to answer the second research question of why potential female mechanical engineers decide to pursue long-term careers in that male-oriented profession. In addition to their previous influences from high school and university courses and experiences, their subsequent academic and career interests played significant roles in the student participants' career decisions and professional development. It is worth noting that without their firm interests in certain career pathway(s), the individuals might have selected other university majors and career opportunities, regardless of their financial and personal decisions (Gibbons \& Borders, 2010). As 
one said, "I like robots and physics ... I study physics and mechanical engineering ... I will become a mechanical engineer ... this is the pathway and how it works ...” (P\#21, Focus Group)

\subsubsection{Interest in interdisciplinary engineering}

Many participants affirmed that their knowledge gained from mechanical engineering broadened their horizons not only in the field of mechanical engineering but also in physics and biological engineering. A previous study (Guerra, 2017) had suggested that an engineering education and profession comprise interdisciplinary subject areas that professionals can apply to different fields and directions. In this study, many participants expressed the belief that their engineering knowledge from mechanical engineering could also be beneficial towards physics, biomedical subjects, mathematics, statistics, and the like. Therefore, their learning and interests were wide and general and followed multiple directions. Two significant sharings were captured,

... unlike computer engineering or civil engineering, with detailed focuses, ... mechanical engineering professionals can apply the mathematics skills to multiple industries ... from the factories, hospitals, railroads, interior design and medical supplies ... I am not only focusing on one knowledge but multiple [types of] knowledge at the same time ... (P\#6, Focus Group)

... I think mechanical engineering can provide me different learning opportunities in different subject matters ... I only learn some biomedical engineering and technique from the medical perspectives ... as mechanical engineers always deal with medical factors and experts ... I can learn some knowledge from the motor engineering courses and experts ... the opportunities are wide and general but with focused direction ... (P\#13, Interview)

\subsubsection{Potential for career development and opportunities in the future robot industry}

Several participants expressed the feeling that potential career opportunities in mechanical engineering, the robot industry, and green energy could increase their interests in following this career pathway for long-term development. A recent report (Shirvani, 2020) stated that employers always admire professionals with mechanical engineering skills and are willing to invest resources in individuals early in the start of such a career. The field has great potential for long-term development. Two participants expressed their thinking about how to combine the value of their mechanical engineering knowledge with a basis in their gender as women, saying,

... many of the electric vehicles and green cars are designed by men ... some of the comments, size, application of the engine or the motor are not female-friendly ... the factories and engineers need to listen to female engineers' voices ... and female professionals need to join the discussion ... I can see the management and organisational leadership are going to answer it ... therefore, the female professionals are in demand now ... (P\#5, Interview)

Many female people are using some of the motor or electronics ... for example many women operated lawn mowers ... but the current mowers were too large and heavy ... why can't we design a female-friendly machines for them ... we can see some machines were designed for female ... smaller or so ... I want to bring these voices to the field (P\#9, Interview)

Another section of feedback was about the future development of nonhuman machines and robot designs in response to the population ageing that is occurring in many developed countries and regions. Although such countries may invite overseas workers as labourers, robots ultimately will lead the medical and hospitality industries (Hebesberger et al., 2017). Because of this trend, the participants asserted that career development in the robot industry, and particularly in the replacement of nursing professionals, will become a significant industry in the near future. Furthermore, many believed they would have an advantage as women and that the development of robots to function as nursing 
professionals will become vital. One said,

... some robots in the hospitals are going to replace nurses ... they need to take care of the patients ... I think women may have a better sense ... about how to design these robots and machines ... women have the sense of caring which men don't have ... that's why many organisations are aggressively hiring female mechanical engineers ... (P\#8, Interview)

In short, joining a profession and an industry is not an easy step for many individuals, particularly university students who do not have any working experience (Dos Santos, 2019). Therefore, an understanding of the connection between students' sense-making processes for their university major and their career choices and desires is important for guiding the design of human resources planning and engineering programmes. In accordance with the guidelines of the Social Cognitive Career Theory (Dos Santos, 2020; Lent et al., 1994; Lent \& Brown, 1996), many participants believed that their perspectives as female users could help them use their gender as an advantage for merging and improving results, outcomes, and designs in mechanical engineering, such as for vehicles and robots (Firdaus et al., 2020). More important, many expressed their interest and long-term career development goals in this field, regardless of the field's social stereotypes and social stigma (Wu et al., 2020). Because most believed that their own personal interests and desires for long-term professional development should be their priorities in making career decisions, the community members' voices would not influence their choices.

\section{Limitations and Future Research Developments}

Each research study has its limitations. However, these limitations may build up potential future research directions. Firstly, the current study employed the case study methodology within a university environment. As the United States is one of the largest countries with more than 3,ooo universities, students from different regions may have different ideas and sharing. Therefore, future researchers may expand the sites as the regional or national reports in order to increase the density of the study. Secondly, although female students and female engineers are important in the field of mechanical engineering, other minorities, such as professional with colour, may face a similar problem. Therefore, future research studies may focus on professionals with other unique background. Thirdly, the field of mechanical engineering may be limited as there are other subject matters and majors may face a similar problem. Therefore, the expansion to other subject matters may be useful.

\section{Conclusions and Practical Implications}

Most of the current mechanical engineering profession's results and engineering education studies have focused on improving and increasing the profession's achievements and outcomes, from the basis of quantitative data and statistics. Only a few studies have focused on the qualitative feedback and comments from female mechanical engineering students reporting their ideas and thinking regarding their selection of mechanical engineering as a university major and career decision. This study's results enable engineering school leaders and department heads to reform their curricula and instructions for female students and their internship directions for students, from multiple perspectives.

In addition, human resource planners, government leaders, and policymakers will benefit from our findings, because this study outlines in detail the lived stories and sharings from female engineering students, describing their experiences, sense-making processes, and career decisions. This study's results will allow educational leaders to reform and enhance current human resource planning and labour market management for the next decade. Because the demand for professionals in mechanical engineering and its related robot industry is increasing, long-term planning for human resource training will be essential. 


\section{Acknowledgement}

The study was supported by Woosong University Academic Research Funding 2021.

\section{References}

Annabi, H., \& Lebovitz, S. (2018). Improving the retention of women in the IT workforce: An investigation of gender diversity interventions in the USA. Information Systems Journal, 28(6), 1049-1081. https://doi.org/10.1111/isj.12182

Basten, M., Meyer-Ahrens, I., Fries, S., \& Wilde, M. (2014). The effects of autonomy-supportive vs. controlling guidance on learners' motivational and cognitive achievement in a structured field trip. Science Education, 98(6), 1033-1053. https://doi.org/10.1002/sce.21125

Cech, E., \& Rothwell, W. (2018). LGBTQ inequality in engineering education. Journal of Engineering Education, 107(4), 583-610. https://doi.org/10.1002/jee.20239

Dos Santos, L. M. (2019). Engineering education as a second career: The experience of female practising engineers. Global Journal of Engineering Education, 21(3), 202-207.

Dos Santos, L. M. (2020). The relationship between the COVID-19 Pandemic and nursing students' sense of belonging: The experiences and nursing education management of pre-Service nursing professionals. International Journal of Environmental Research and Public Health, 17(16), 5848. https://doi.org/10.339o/ijerph17165848

Firdaus, R., Abdullah, A., \& Sumarto, S. (2020). Women in mechanical engineering at vocational high school. IOP Conference Series: Materials Science and Engineering, 830, 042063. https://doi.org/10.1088/1757$899 \mathrm{X} / 830 / 4 / 042063$

Fuesting, M., Diekman, A., \& Hudiburgh, L. (2017). From classroom to career: The unique role of communal processes in predicting interest in STEM careers. Social Psychology of Education, 20(4), 875-896. https://doi.org/10.1007/s11218-017-9398-6

Gibbons, M. M., \& Borders, L. D. (2010). Prospective First-Generation College Students: A Social-Cognitive Perspective. The Career Development Quarterly, 58(3), 194-208. https://doi.org/10.1002/j.21610045.2010.tboo186.x

Guerra, A. (2017). Integration of sustainability in engineering education. International Journal of Sustainability in Higher Education, 18(3), 436-454. https://doi.org/10.1108/IJSHE-02-2016-0022

Harvey, D., Greer, D., Basham, J., \& Hu, B. (2014). From the student perspective: Experiences of middle and high school students in online learning. American Journal of Distance Education, 28(1), 14-26. https://doi.org/10.108o/08923647.2014.868739

Hebesberger, D., Koertner, T., Gisinger, C., \& Pripfl, J. (2017). A long-term autonomous robot at a care hospital: A mixed methods study on social acceptance and experiences of staff and older adults. International Journal of Social Robotics, 9(3), 417-429. https://doi.org/10.1007/s12369-016-0391-6

Hernandez-de-Menendez, M., \& Morales-Menendez, R. (2019). Technological innovations and practices in engineering education: A review. International Journal on Interactive Design and Manufacturing (IJIDeM), 13(2), 713-728. https://doi.org/10.1007/s12008-019-00550-1

Lent, R. W., \& Brown, S. D. (1996). Social cognitive approach to career development: An overview. The Career Development Quarterly, 44(4), 310-321. https://doi.org/10.1002/j.2161-0045.1996.tboo448.x

Lent, R. W., Brown, S. D., \& Hackett, G. (1994). Toward a unifying social cognitive theory of career and academic interest, choice, and performance. Journal of Vocational Behavior, 45(1), 79-122. https://doi.org/10.10o6/jvbe.1994.1027

Merriam, S. B. (2009). Qualitative research: A guide to design and implementation. Jossey Bass.

Morgan, D. (1998). The focus group guidebook. SAGE Publications, Inc. https://doi.org/10.4135/9781483328164

Rinke, C. R. (2009). Finding their way on: Career decision-making processes of urban science teachers. Science Education, 93(6), 1096-1121. https://doi.org/10.1002/sce.20339

Roy, J. (2019). Engineering by the numbers. https://ira.asee.org/wp-content/uploads/2019/o7/2018-Engineering-byNumbers-Engineering-Statistics-UPDATED-15-July-2019.pdf

Shirvani, K. (2020). ASME early career leadership intern program to serve engineering (ECLIPSE): A talent pipeline model for developing early career mechanical engineers into future leaders. 2020 ASEE Virtual Annual Conference Content Access Proceedings, 1-6. https://doi.org/10.1826o/1-2--34168 
Strachan, R., Peixoto, A., Emembolu, I., \& Restivo, M. (2018). Women in engineering: Addressing the gender gap, exploring trust and our unconscious bias. 2018 IEEE Global Engineering Education Conference (EDUCON), 2088-2093. https://doi.org/10.1109/EDUCON.2018.8363497

Strauss, A., \& Corbin, J. M. (1990). Basics of qualitative research: Grounded theory procedures and techniques. Sage.

Tao, Y. (2018). Earnings of academic scientists and engineers: Intersectionality of gender and race/ethnicity effects. American Behavioral Scientist, 62(5), 625-644. https://doi.org/10.1177/o002764218768870

Weston, T., Dubow, W., \& Kaminsky, A. (2020). Predicting women's persistence in computer science- and technology-related majors from high school to college. ACM Transactions on Computing Education, 2o(1), 116. https://doi.org/10.1145/3343195

White, S. (2018). African american, hispanic, and native American women earning bachelor's degrees in engineering fields. The Physics Teacher, 56(4), 202-202. https://doi.org/10.1119/1.5028230

Women in the labor force: A databook. (2019). https://www.bls.gov/opub/reports/womensdatabook/2019/home.htm

Wu, D., Park, J., \& Dasgupta, N. (2020). The influence of male faces on stereotype activation among women in STEM: An ERP investigation. Biological Psychology, 156, 107948. https://doi.org/10.1016/j.biopsycho.2020.107948

Yin, R. K. (2012). Applications of Case Study Research (3rd ed.). SAGE Publications. 